\title{
ИЗМЕРЕНИЯ СТАТИСТИЧЕСКИХ ХАРАКТЕРИСТИК ПРИРОДНОГО СВЕТОВОГО ПОЛЯ НАД МОРЕМ
}

\author{
A. PURGA, LOODUSLIKU VALGUSVÄLJA STATISTILISTE KARAKTERISTIKUTE MOOTMINE \\ MERE KOHAL \\ A. PURGA. ON MEASURING THE STATISTICAL PARAMETERS OF THE NATURAL LIGHT FIELD \\ ABOVE THE SEA SURFACE
}

\section{(Представил К. К. Ребане)}

Естественное световое поле над отражающей волнистой поверхностью моря даже в относительно устойчивых условиях освещения описывается как существенно случайный процесс. Характеристики этого процесса до сих пор мало изучены. Измерения яркости моря фотометрами с временами интеграции, значительно превышающими временные характеристики коротких поверхностных волн, дают величины, пропорциональные средней случайного поля яркости. Однако для характеристики даже простейшего случайного процесса с нормальным законом распределения требуется, кроме среднего значения, и величина дисперсии. Разовые измерения быстродействующими фотометрами поставляют единичный результат из совокупности случайных величин, который в принципе не может служить характеристикой случайного процесса в целом.

В 14-й и 17-й экспедициях научно-исследовательского судна «АюДаг» в августе 1979 г. и в апреле-мае 1980 г. были получены оценки первых четырех моментов и частотная гистограмма распределения яркости.моря как случайной величины на более чем двухстах оптических измерительных станциях. Измерения осуществлялись специальным судовым фотометром MC-1, сконструированным и построенным Институтом астрофизики и физики атмосферы и Институтом термофизики и электрофизики. Быстродействие и математическое обеспечение фотометра MC-1 позволяли за время предполагаемой квазистационарности исследуемого процесса $(100 \mathrm{c})$ получать необходимый для статистической обработки массив единичных измерений (50 или 100 со станции). На семи спектральных полосах (с максимумами при 392, 432, 526, 547, 620,673 и 700 нм и шириной около 8 нм) измерялись яркость водной поверхности и облученность. Характерный набор значений яркости моря с одного спектрального канала изображен в виде временного ряда на рис. 1.

Рис. 1. Последовательность значений яркости моря за сеанс измерения $(100$ c).

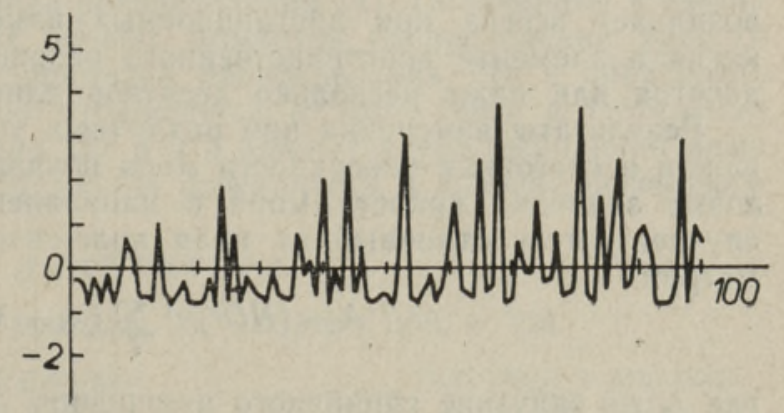



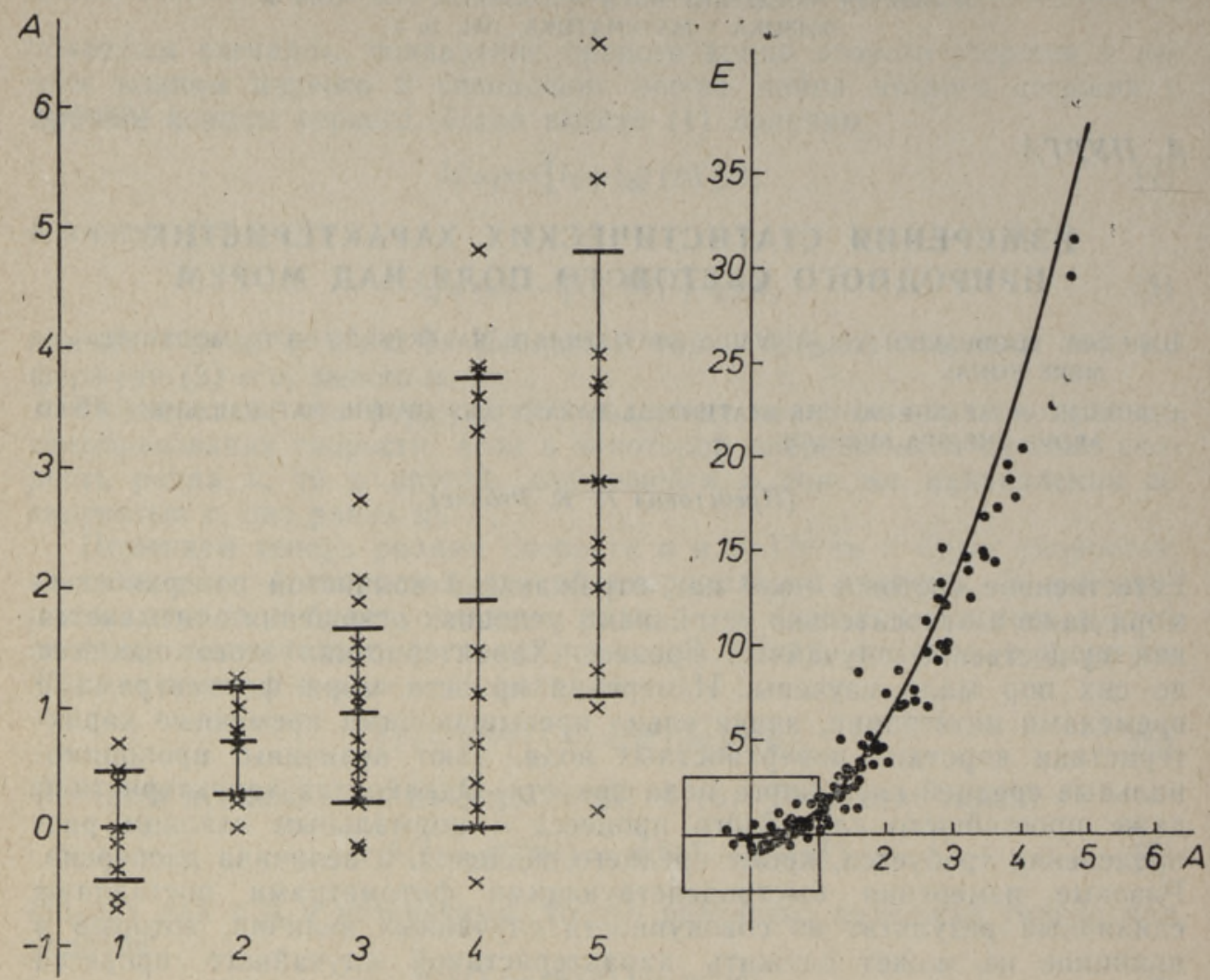

Рис. 2. Диаграмма зависимости коэффициента асимметрии $A$ от условий освещения моря: 1 - сплошная плотная облачность; 2 - сплошная облачность, днск солнца виден, тени нет; 3 - сплошная облачность, тень видна; 4 - около солнца облаков нет; 5 - безоблачное небо.

Рис. 3. Зависимость коэффициента эксцесса $E$ от коэффициента асимметрии $A$. Точки обозначают экспериментальные значения, сплошная линия $-E=1,5, A^{2}$.

Во время измерений блок приемника фотометра был закреплен на вынесенной за корму судна балке (высота над морем 5 м, расстояние от кормы $1,5 \mathrm{M}$ ). Морской канал фотометра при такой установке собирал поток излучения с участка морской поверхности диаметром около 1 м. Таким образом, за время единичного измерения в поле зрения прибора попадал участок, включающий в себя, как правило, целый набор ориентированных в разные направления элементарных «зеркал» коротких ветровых волн. Аналогичная ситуация практически возникает всегда при дистанционных измерениях с больших высот, когда в элементе пространственного разрешения прибора помещается десяток или даже несколько десятков длинных ветровых волн.

Результаты измерения при различных условиях естественного освещения и состояния поверхности моря показали, что функция распределения значений яркости моря в направлении зенита в большинстве случаев имеет отличный от нуля положительный коэффициент асимметрии

$$
A=\left(N D^{3}\right)^{-1} \sum_{i}\left(x_{i}-\bar{x}\right)^{3}
$$


выборке, $D$ - дисперсия выборки, $N$ - число измерений в выборке. Исключение составляют измерения, выполненные при пасмурной погоде в условиях плотной сплошной облачности, когда $A \approx 0$. На рис. 2 четко прослеживается тенденция к увеличению $A$ с увеличением доли направленного излучения (от пасмурной к безоблачной солнечной погоде). Таким образом, в интересных для дистанционных оптических измерений случаях (ясная погода) яркость моря как случайная величина не описывается нормальным (гауссовым) распределением.

Сравнение оценок для коэффициентов асимметрии $A$ и эксцесса $E$, где $E$ определяется как

$$
E=\left(N D^{4}\right)^{-1} \sum_{i}\left(x_{i}-\bar{x}\right)^{4}-3
$$

показывает, что в наших измерениях существует приближенная зависимость

$$
E=1,5 A^{2} \text {. }
$$

Коэффициент корреляции между экспериментальными значениями $E$ и вычисленными значениями $1,5 A^{2}$ превышает 0,95 (рис. 3 ). Зависимость (3) характерна для обобщенного гамма-распределения $\left[{ }^{1}\right]$ :

$$
\begin{gathered}
f(x ; \alpha, \beta, p)=(\beta \Gamma(\beta))^{-1} y^{p-1} \mathrm{e}^{-y}, \\
y \equiv(x-\alpha) / \beta, \quad \alpha \leqslant x \leqslant \infty, \quad-\infty<\alpha<\infty \\
0<\beta^{\prime}<\infty, \quad 0<p<\infty .
\end{gathered}
$$

Здесь $\alpha, \beta$ и $p$ - параметры распределения,

гамма-функция.

Объяснить асимметрию закона распределения эмпирической яркости моря можно следующим образом. Для прибора дистанционных измерений, одновременно охватываюшего целый набор уклонов реальной морской поверхности, зеркально отраженный прямой солнечный свет является, как правило, естественной частью яркости моря в околозенитном направлении. Распределение же солнечных бликов в поле зрения прибора по числу и яркости не обязательно является нормальным.

Известный закон распределения яркости (4), обусловленной отражением от поверхности, дает принципиально новую возможность выделения доли солнечных бликов из суммарного сигнала. Предположим, что яркость моря в направлении зенита в первом приближении складывается из яркости подповерхностной толщи воды и отраженного от поверхности прямого солнечного излучения. За краткое время измерения на станции (около $100 \mathrm{c}$ ) оптические свойства воды и соответствующую яркость $\alpha$ диффузно отраженного от подповерхностного слоя воды света можно считать постоянными. Тогда значение яркости $\alpha$ совпадает с нижней границей распределения (4). Полученные в наших измерениях оценки четырех первых моментов распределения яркости позволяют вычислить три параметра распределения (4) и определить тем самым яркость диффузно отраженного от моря света $\alpha$. Остальные два параметра распределения (4) $\beta$ и р являются при выбранной нами модели характеристиками состояния поверхности и условий освещения.

\section{Л ИТ Е Р А У Р А}

1. Справочник по специальным функциям, М., «Наука», 1979, с. 726. 